\title{
La argumentación científica escolar: contribución a la comprensión de un modelo complejo de salud y enfermedad
}

\author{
School scientific argumentation: a contribution \\ to the understanding of a complex model of health and disease
}

\author{
Andrea Fernanda Revel Chion ${ }^{1}$. Elsa Meinardi ${ }^{1}$. \\ Agustín Adúriz Bravo ${ }^{1}$
}

\begin{abstract}
Resumen: Este trabajo aborda la relación existente entre el aprendizaje de la argumentación científica escolar y la adquisición de un modelo complejo en torno a la salud y la enfermedad, más específicamente para la explicación de la emergencia o reemergencia de las enfermedades. Se asume que la argumentación científica escolar es un procedimiento cognitivo lingüístico que da lugar a la producción de un texto que explica, en el que pueden reconocerse cuatro componentes: pragmática, retórica, teórica y lógica. Se realizó un análisis histórico-epistemológico del concepto de salud y se tomó posición por un modelo complejo, que hemos denominado multicausal y multirreferencial. Se diseñó una unidad didáctica para la enseñanza de ambos contenidos con énfasis en procesos metacognitivos y autorregulatorios puestos en marcha pr medio de bases de orientación, e instancias de autoevaluación, coevaluación y heteroevaluación. El estudio realizado se alinea en un modelo de explicación ilocutivo.
\end{abstract}

Palabras clave: Argumentación científica. Modelo multicausal y multirreferencial. Salud. Enfermedad.

\begin{abstract}
This paper explores the existing relationship between the learning of school scientific argumentation and the acquisition of a complex model of health and diseases, more specifically to explain the emerging and re- emerging of diseasess. It is assumed that school scientific argumentation is a linguistic-cognitive procedure that gives rise to the production of a text that explains a topic in which four key domains can be recognised: pragmatics, rethoric, theory and logics. A historic-epistemological analysis of the concept of health was carried out and position was taken in favour of a complex model that we have defined as multicausal and multireferential. For both contents a didactic model unit has been designed, laying emphasis on the metacognitive and self-regulatory processes set into motion through the basis of orientation and instances of self-evaluation, co- evaluation and hetero-evaluation. The study is brought into line with a model of illocutionary explanation.
\end{abstract}

Keywords: Scientific argumentation. Multicausal and multireferential model. Health. Disease.

\footnotetext{
${ }^{1}$ Centro de Formación e Investigación en Enseñanza de las Ciencias (CeFIEC), Facultad de Ciencias Exactas y Naturales (FCEyN), Universidad de Buenos Aires (UBA), Avenida Elcano 3929, Ciudad Autónoma de Buenos Aires, CP 1427, Buenos Aires, Argentina. E-mail: <andrearevelchion@yahoo.com.ar>
} 


\section{Introducción}

En el año 2000, Rosalind Driver, junto a Paul Newton y Jonathan Osborne, publicaron en la revista Sience Education un artículo que para muchos fue fundacional: "Establishing the norms of scientific argumentation in classrooms". En él, los autores denunciaban las escasas oportunidades que tenían los estudiantes para practicar argumentaciones en las clases de ciencias y los también deficientes conocimientos pedagógicos de los profesores acerca de la cuestión. Una de las razones que impedía progresar en el campo lo constituía, según su criterio, la escasa atención que desde la enseñanza de las ciencias se había prestado a la argumentación. Los autores afirmaban que se debía ayudar a los estudiantes a reconocer la importancia de los argumentos científicos y, en ese sentido, la enseñanza de las ciencias debería proponer instancias para su aprendizaje y práctica. Sólo esas prácticas, enfatizaban Driver y sus colegas, serían las formas de familiarizar a los estudiantes con las argumentaciones científicas, les aportarían confianza en su uso y les proveería de una comprensión más profunda acerca del rol de las mismas en la producción del conocimiento científico. Finalizaban el artículo afirmando que la argumentación tiene un papel central en la producción científica y en el aprendizaje de las ciencias, y que su omisión en el currículo escolar constituía un problema que necesitaba ser encarado.

La investigación en didáctica de las ciencias naturales ha prestado en la última década especial atención a la línea de investigación relacionada con el lenguaje y la enseñanza de las ciencias, dentro de la cual se destaca la argumentación. Dichas investigaciones han revelado el papel que la argumentación puede jugar en diferentes planos del aprendizaje y ha motivado la reflexión de profesores de nivel secundario, terciario y universitario, e investigadores en didáctica especializados en dichos niveles.

En los estudios en torno de la argumentación conviven diferentes concepciones.; así, Jiménez Aleixandre (2010) define la argumentación como la capacidad de evaluar enunciados con base a pruebas. El grupo Lectura y Escritura en Enseñanza de las Ciencias (LIEC) de la Universidad Autónoma de Barcelona la define como una actividad social, intelectual y verbal que sirve para justificar o refutar una opinión y que consiste en hacer declaraciones teniendo en cuenta al receptor y la finalidad con la cual se emiten. "Para argumentar hace falta elegir entre diferentes opciones o explicaciones y razonar los criterios que permiten evaluar como más adecuada la opción elegida”. (SANMARTÍ, 2003, p. 23).

En el marco de este trabajo se asumió la denominación argumentación científica escolar, deudora del modelo cognitivo de ciencia escolar (IZQUIERDO et al., 1999), entendida como un procedimiento - de tipo cognitivo lingüístico - que da lugar a la producción de un texto que explica, en el cual se subsume un fenómeno natural bajo un modelo teórico por medio de un mecanismo de naturaleza analógica (ADÚRIZ-BRAVO, 2011; MEINARDI et al., 2004; REVEL CHION, 2010; REVEL CHION et al., 2005; REVEL CHION; ERDURAN; ADURIZBRAVO, 2004). En un texto explicativo pueden reconocerse cuatro componentes: pragmática (la adecuación al contexto), retórica (la intención de persuadir al receptor), teórica (el ajuste al modelo teórico de referencia) y lógica (la estructura sintáctica del texto).

De acuerdo con Adúriz-Bravo (2011) el aprendizaje de la argumentación científica escolar supone aprender coordinadamente tres aspectos: a argumentar, en qué consiste una argumentación y sus particularidades desde el punto de vista lingüístico. A su vez, Sanmartí (2007) sostiene que son necesarias instancias de enseñanza explícitas de la argumentación, es decir, 
enseñar cómo se argumenta y cuáles son las particularidades de esta tipología textual, poniendo la práctica de esta destreza en relación con los contenidos científicos escolares que, en el caso del presente trabajo, son aquellos relacionados con un modelo complejo de salud-enfermedad.

Esta investigación abordó la enseñanza de la argumentación científica escolar y su impacto en la apropiación por parte de los estudiantes de un modelo multicausal y multirreferencial para la explicación de la emergencia de las enfermedades. Los casos a analizar bajo dicho modelo fueron presentados a los estudiantes en formato narrativo. Se exponen entonces tres aspectos en relación a los fundamentos teóricos: uno referido a la argumentación y los objetivos alcanzables por su intermedio, otro relativo a la perspectiva de salud-enfermedad asumida y, finalmente, uno destinado al formato narrativo utilizado para la presentación de los casos presentados a los estudiados en este trabajo.

\section{Objetivos de aprendizaje alcanzables por medio de la argumentación}

Reconocidos los aportes de la argumentación científica escolar a los aprendizajes, en este apartado se hace foco en algunos objetivos que podrían ser alcanzados por su intermedio.

\section{Argumentación para desarrollar conocimientos acerca de la naturaleza de la ciencia}

En la actualidad se acepta que en la construcción del conocimiento científico se establece un complejo proceso de negociaciones entre los miembros de la comunidad por medio del cual se comunican los modelos teóricos con el fin de ser validados (SANMARTÍ, 1997; SUTTON, 1997). En esa misma dirección, en la construcción de la ciencia escolar la discusión de las ideas y el uso del lenguaje, con explícitos objetivos retóricos, favorece que los estudiantes comprendan la propia racionalidad de la ciencia e identifiquen los contextos de justificación como los modos de validación de las hipótesis teóricas. (SARDÁ; SANMARTÍ, 2000).

La ciencia frecuentemente avanza por medio de disputas, conflictos y argumentaciones y, en este sentido, la elaboración y comunicación de argumentos se constituyen en el corazón de la empresa científica (ERDURAN; JIMÉNEZ ALEIXANDRE, 2008; ERDURAN; SIMON; OSBORNE, 2004). La enseñanza de la argumentación en las clases de ciencias, es decir la inclusión del lenguaje y en especial el escrito, hace posible que los estudiantes se familiaricen con ciertas particularidades de la ciencia tales como la comunicación de las ideas teóricas con un propósito persuasivo.

\section{La evaluación de los aprendizajes}

En toda actividad, el lenguaje es imprescindible para comunicar y compartir objetivos y explicaciones a la vez que actúa como regulador ya que dirige el pensamiento, ayuda a explicitarlo y puede ser útil para analizarlo y valorarlo, es decir, para evaluarlo (JORBA; GÓMEZ; PRAT, 1998). La escritura de textos argumentativos puede constituirse en una operación epistémica básica de cualquier situación de aprendizaje (DUSCHL, 2008), lo que conduce a justificar su 
uso como una forma de evaluación de los logros alcanzados. En la misma línea, tal como sugiere Kuhn (2010) la argumentación puede ser considerada una ventana por la cual acceder a los modos de pensar de los estudiantes y sus producciones como una forma viable de valorar sus aprendizajes.

Los profesores pueden evaluar los textos que producen sus alumnos con criterios que deben ser consensuados y comunicados. Estos criterios pueden ser de realización o de resultado, es decir, tener en cuenta los aspectos o actuaciones que deben ser puestos en juego para la producción de un texto o tener en cuenta si el texto elaborado cumple determinas condiciones propias de la tipología textual a la que pertenece. Cuando los profesores evalúan la producción de sus alumnos recurren a criterios de realización y de resultado que pueden incluir, la conceptualización acerca de qué es una argumentación, qué elementos debe contener y qué recursos deben utilizarse para construirla (JORBA; GÓMEZ; PRAT, 1998).

\section{Lectura y escritura en las disciplinas}

El movimiento Writing Across the Curriculum (WAC) o escritura en las disciplinas se inició en 1970 en los Estados Unidos con foco en las prácticas pedagógicas del ámbito universitario; en la actualidad se profundiza también en la lectura y la escritura en la escuela secundaria, en la línea "Talk and writing in secondary science" (KEYS, 1999; PRAIN; HAND, 1999; RIVARD; STRAW, 2000). El interés del movimiento se centra en identificar las características diferenciales que asume la escritura a lo largo de las disciplinas. La concepción de que escribir contribuye a aprender (writing to learn) se basa en la observación de que la comprensión y el pensamiento de los estudiantes se afianza y clarifica con la participación en actividades que la involucre. Langer y Applebee (1987) sugieren que la escritura en las disciplinas promueve mejores aprendizajes que las actividades que sólo involucran la lectura ya que conducen a los estudiantes a tener en cuenta en sus escritos diferentes tipos de informaciones y estimulan la producción de textos más meditados, analíticos y complejos, en contraste con las actividades que exigen respuestas cortas que, por lo tanto, atomizan la información.

Dentro de los diferentes tipos de textos, los argumentativos tienen una particular relevancia para el aprendizaje, en tanto exigen la elaboración de conclusiones en base a datos significativos y la inclusión de proposiciones que sean susceptibles de apoyar y conducir a dichas conclusiones. Las proposiciones presentadas exhiben un status epistémico que puede ser evaluado simultáneamente con la eficiencia que muestra el encadenamiento y relación de dichas proposiciones en su función persuasiva. (KELLY; TAKAO, 2002; SAMPSON; CLARK, 2008;).

\section{Argumentación para el desarrollo de habilidades de pensamiento de orden superior}

Numerosas investigaciones señalan la importancia de la argumentación en el aprendizaje (DRIVER; NEWTON; OSBORNE, 2000; IZQUIERDO; SANMARTI, 2001; JIMÉNEZ ALEIXANDRE; DÍAZ DE BUSTAMANTE, 2003). Dentro de los marcos teóricos que interpretan dicha importancia, la perspectiva sociocultural, representada principalmente por Lev Vygotsky (1977), enfatiza el rol que la interacción social juega en el aprendizaje y los procesos de pensamiento. 
El desarrollo de los procesos psicológicos superiores, se genera con la mediación de las actividades sociales, muy particularmente con la mediación del lenguaje.

La relación entre pensamiento y palabra no es un hecho sino un proceso, un ir y venir continuado del pensamiento a la palabra y de la palabra al pensamiento $[\ldots]$ el pensamiento no se expresa simplemente en palabras, sino que existe a través de ellas. (VYGOTSKY, 1977, p. 166)

La escritura escolar requiere de una serie de acciones de acuerdo a patrones culturales definidos que son mostrados y facilitados por los profesores, lo que implica la puesta en marcha y desarrollo de habilidades cognitivas y sociales por parte de los alumnos; simultáneamente se asimilan los contenidos incluidos en el currículo. El dominio del lenguaje hace posible la transformación del mundo interior, la formación de los procesos psicológicos superiores (atención conciente, memoria voluntaria, razonamiento y lenguaje). El uso del lenguaje hace posible controlar y regular el propio comportamiento de modo conciente; el lenguaje verbal hace posible al mismo tiempo planificar, es decir, decidir los pasos de acciones, preparar un texto, etc.

Construir un discurso argumentativo para expresar un conocimiento supone establecer las relaciones entre los elementos que participan en dicho conocimiento y expresarlo utilizando un lenguaje que sea comprendido por el receptor; es en todo dicho proceso en que se produce una reelaboración y regulación profunda del contenido. Es este hecho el que conduce a afirmar que el lenguaje juega un rol fundamental en la construcción del aprendizaje (MÁRQUEZ, 2008, p. 76)

\section{El desarrollo del pensamiento crítico}

Jiménez Aleixandre (2010) define pensamiento crítico como la capacidad de reflexión acerca de asuntos sociocientíficos y la intervención en la sociedad, entendiendo como asuntos de este tipo a aquellos dilemas sociales que demandan decisiones políticas, institucionales o personales, es decir, que forman parte de la ciencia pero que encarnan controversias de tipo social. Así, la ciencia se implica en un debate social por lo que se incluyen en ella aspectos éticos, económicos, ambientales. Estos dilemas ostentan una profunda complejidad y tienen estrecha relación con la sociedad por lo que trascienden la ciencia pura, es decir, que exigen explicaciones científicas pero puestas en relación con el impacto que dichos asuntos tienen en la sociedad.

Las ciudadanas y ciudadanos necesitan ser capaces de poder hablar y comprender el lenguaje de las ciencias para participar, aunque no sea activamente sino sólo mentalmente, de los debates sobre temas científicos que los involucre; al mismo tiempo conocer este lenguaje es necesario para identificar las diferencias entre ciencias y pseudociencias y evitar así que las personas por no saber se retiren a posiciones de fe ciega o den crédito a publicaciones de sospechosa autoridad. (CLAXTON, 2001, p. 154) 


\section{Un modelo escolar de salud-enfermedad}

Los contenidos relacionados con la salud y la enfermedad, suelen ser abordados en las instituciones educativas del nivel secundario a partir de enfoques biologicistas o simplificados, es decir, desde perspectivas perimidas o insuficientes para exponer la complejidad que las atraviesa. En función de este hecho se propuso un modelo explicativo para el origen de las enfermedades superador del enfoque biologicista hegemónico (MAGLIO, 2008) y, al mismo tiempo, se asumió un concepto de ambiente en sentido amplio, que incluye a los determinantes sociales, y fuertemente vinculado a la salud y a la enfermedad (MEINARDI; GONZÁLEZ GALLI, 2009).

En el marco de este trabajo se ha considerado que los modelos imperantes - que enfatizan las descripciones de las noxas, básicamente las biológicas, las sintomatologías y las medidas de prevención - son insuficientes para dar cuenta del carácter complejo del binomio salud-enfermedad desde el punto de vista de las demandas actuales del currículo de muchos países, tales como la participación ciudadana, el espíritu crítico y la consiguiente toma de decisiones justificadas y una inmersión adecuada en la cultura. En este sentido el modelo multicausal y multirreferencial propuesto y enseñado a los estudiantes en el marco de esta investigación mostró responder a la complejidad aludida, en especial en lo que se refiere a establecer las relaciones entre las variadas causas (multicausalidad) que se conjugan para la emergencia y reemergencia de las enfermedades.

\section{Las narrativas}

El modelo de salud asumido en esta investigación exige datos provenientes de diferentes disciplinas y el formato narrativo, en función de sus particularidades, evidenció ser una estructura adecuada para la presentación de los casos ya que aportó a los aspectos vertebradores del modelo asumido: la multirreferencialidad y la multicausalidad.

Bruner (1991) califica de "emblemática" la capacidad de las narrativas para aportar conocimientos generales, además de los sucesos singulares que ellas relatan; en este sentido afirmará: "Esto las hace vehículos de conocimiento adecuado para disciplinas diversas, sobre todo las que lidian con complejidades históricas y causales de alto calibre, entre ellas la biología y la medicina". (BRUNER, 1991, p. 13).

Así, las narrativas se constituyeron en una estrategia didáctica acertada porque resultaron un medio eficaz para la inclusión de los diferentes aspectos de los casos presentados, lo que facilitó la comprensión de dos elementos pilares del modelo de salud presentado: la complejidad del ambiente y la inseparable relación de éste con la emergencia y reemergencia de las enfermedades. Como plantea Wasserman (2006) los relatos se centran en temáticas específicas pero son, por naturaleza, interdisciplinarios.

En segundo lugar el formato narrativo cumplió con el reconocido rol motivador, captador de atención (NORRIS, 2005) y en función de su memorabilidad (JACKSON, 2005) los datos que aportan fueron recuperados por los estudiantes en la construcción de los textos argumentativos que les fueron requeridos a lo largo de la unidad didáctica de esta investigación.

Finalmente, en relación con la potencia de la instrumentación de los relatos en la enseñanza, la estructura narrativa puede subsanar las limitaciones de la formación inicial de los profesores - al menos en nuestro país - que podrían atentar contra la implementación del 
modelo de salud-enfermedad presentado en este trabajo, ya que el mismo demanda conocimientos biológicos, ambientales, históricos, geográficos y económicos, entre otros, con los que los profesores podrían no contar o dominar adecuadamente en virtud de estar ausentes en los programas de formación inicial.

\section{Metodología y análisis de los datos}

Se ha implementado una metodología cualitativa y se ha trabajado con dos cursos correspondientes a quinto año (16-17 años) de la escuela secundaria; la misma está ubicada en la Ciudad Autónoma de Buenos Aires, capital del país. La investigación se desarrolló en el marco de la asignatura "Educación para la salud" a cargo de la docente-investigadora en la terminología de Kemmis y Mc'Taggart (1988).

El trabajo se alinea con la corriente de investigación basada en las secuencias de enseñanza aprendizaje - que en el ámbito de habla hispana se denominan más extendidamente "unidades didácticas". La misma se enmarca en una tradición de investigación de la educación científica en la que la enseñanza y el aprendizaje son investigados a "micro-nivel" tal como la secuencia de un sólo tema, en lugar de los más tradicionales estudios a nivel macro como un currículum o un curso completo. Una característica distintiva de estas actividades investigativas es su carácter dual que implica tanto objetivos de investigación como objetivos en relación con la enseñanza y el aprendizaje de un tema en particular. Las secuencias de enseñanza de este tipo, se anclan en la tradición de investigación-acción usándose tanto como herramientas de investigación como herramientas innovadoras que apuntan al abordaje de problemas de aprendizaje relacionados con temas puntuales. (MÉHUET; PSILLOS, 2007).

La unidad didáctica diseñada e implementada se erigió en una estructura secuenciada, en la que se presentaron las componentes de una argumentación y, en función de las mismas, se elaboró, en forma conjunta, una base de orientación ${ }^{2}$, instrumento que deriva de la Teoría de la Actividad propuesta por Leontiev. La misma ofició de elemento regulador de las producciones argumentativas sugeridas a los estudiantes, es decir, que aportaron criterios para tomar decisiones acerca de los modos de elaborarlas y evaluarlas.

La secuencia didáctica incluyó la enseñanza del modelo de salud-enfermedad asumido para lo cual se presentó la evolución experimentada por dichos conceptos a lo largo del tiempo. Desde la perspectiva en la que se posiciona este trabajo resultaba ineludible precisar el concepto de ambiente en sentido amplio y en estrecha relación con la salud, razón por la cual también se presentó a los estudiantes dicha perspectiva.

Los estudiantes elaboraron argumentaciones en distintos formatos a diferentes receptores y para diferentes contextos, en consonancia con el modelo ilocutivo que se asumió en

\footnotetext{
${ }^{2}$ La base de orientación elaborada en forma conjunta fue la siguiente: (1) Intención o voluntad de convencer al receptor; (2) Tener en cuenta a quién va dirigido: vocabulario y considerar el contexto social y tiempo de la explicación; (3) Tener en cuenta el marco teórico; (4) Utilizar conectores para indicar las relaciones causales: por que, así, de este modo, por lo tanto, pero, como pues; (5) Incluir una conclusión, tener presente que la misma sea coherente con los datos. Lista de conectores para iniciar la conclusión: finalmente, por ende, en conclusión, podemos concluir, en resumen.
} 
Chion, A. F. R.; Meinardi, E.; Adúriz Bravo, A.

este trabajo (Cuadro 1). El modelo de explicación pragmático-ilocutivo surge en los años 50 y propone considerar a los usuarios del lenguaje y fundamentalmente los contextos de uso. Se afirma que una comunicación es ilocutiva si la misma expresa algo que es comprendido por el receptor y produce en él algún efecto. (EDER; ADÚRIZ BRAVO, 2008; IZQUIERDO; ADÚRIZ BRAVO, 2003).

Cuadro 1. Casos abordados: actividades, receptores y contextos

\begin{tabular}{|c|c|c|c|}
\hline Casos & Actividades & $\begin{array}{l}\text { Contexto de la } \\
\text { explicación }\end{array}$ & $\begin{array}{l}\text { Receptor de la } \\
\text { explicación }\end{array}$ \\
\hline \multirow{3}{*}{$\begin{array}{l}\text { Peste negra } \\
\text { medieval }\end{array}$} & ¿Por qué reaparecen las epidemias? & Escolar & Profesora \\
\hline & ¿Qué dije mientras conversabas? & Escolar & Profesora \\
\hline & $\begin{array}{l}\text { ¿Qué vieron hoy en la clase de educación } \\
\text { para la salud? }\end{array}$ & Informal & Madre \\
\hline \multirow{3}{*}{$\begin{array}{c}\text { Porfiria } \\
\text { eritropoyética } \\
\text { congénita o mal } \\
\text { de Günther }\end{array}$} & Enfermedad genética de un bebé por nacer & Escolar & Profesora \\
\hline & ¿Enfermos o vampiros? & Informal & $\begin{array}{l}\text { Anciana habitante de } \\
\text { los Cárpatos }\end{array}$ \\
\hline & Programa radial de la OMS & Informal & $\begin{array}{l}\text { Diferentes tipos de } \\
\text { oyentes }\end{array}$ \\
\hline \multirow{2}{*}{$\begin{array}{c}\text { Encefalitis por } \\
\text { virus Nipah } \\
\text { SIDA }\end{array}$} & Poster para un congreso de virología & Congreso científico & $\begin{array}{l}\text { Especialistas en } \\
\text { virología }\end{array}$ \\
\hline & Origen del VIH & Examen & Profesora \\
\hline
\end{tabular}

Fuente: elaborado por los autores.

Se propuso la evaluación de las producciones bajo la estructura de coevaluaciones, heteroevalauciones y autoevaluaciones que pretendieron vehiculizar las bases de orientación elaboradas y las estrategias metacognitivas y autorregulatorias.

Se obtuvieron 373 textos argumentativos cuyo análisis se realizó a partir de redes sistémicas, instrumento propuestas por Bliss, Monk y Ogborn (1983), como un método para organizar datos cualitativos provenientes de cuestionarios abiertos, observaciones de aula y entrevistas. Tal coma afirman sus creadores detrás de cada palabra escrita en el contexto de una frase hay un significado no directamente expresado por las palabras (BLISS; MONK; OGBORN, 1983). Las redes sistémicas permiten conectar las diferentes descripciones de los datos con las posibles interpretaciones y establecer relaciones entre los significados; asimismo hacen posible estructurar los datos recogidos de acuerdo con una categorización establecida, resultado de las necesidades u objetivos de la investigación.

Cuando se evalúan las producciones de los alumnos, se tiende a valorar más los resultados que a intentar comprender dificultades o errores; uno de los instrumentos que pueden asistir en el intento de analizar cuál es la lógica de los alumnos son las redes sistémicas. (SANMARTÍ, 2007). 
Las redes sistémicas se confeccionaron y ajustaron con posterioridad a la lectura de los textos de los estudiantes que se pretendía organizar; de dicha lectura surgieron las variables sobre las que se organizaron los datos, con base a categorías escogidas previamente en función del marco teórico a la que adhiere esta investigación. Se construyó una red sistémica para cada una de las actividades y para cada una de las componentes de una argumentación. En el apéndice A se presenta un ejemplo representativo.

\section{Resultados}

El análisis realizado de las producciones textuales de los estudiantes ha permitido concluir que existe una relación positiva entre el aprendizaje de la argumentación científica escolar y la adquisición de un modelo complejo de salud-enfermedad, es decir que la puesta en marcha de la competencia argumentativa contribuye al aprendizaje de contenidos científicos.

Los textos producidos por los estudiantes para los diferentes contextos y receptores que les fueron propuestos, exponen matices en los grados de ajuste de las vertientes multicausales y multirreferenciales, es decir, versiones que superan las clásicas e imperantes visiones biologicistas. Esto permite asumir que el enfoque adoptado puede ser viable para reemplazar las limitaciones de aquellas visiones, imperantes en las instituciones educativas, en relación con las demandas curriculares a las que se hizo mención. En este sentido el análisis de la componente teórica en las instancias de pretest y postest nos indica que al tiempo que sólo dos estudiantes reconocen la relación existente entre salud y ambiente, 33 de ellos lo hacen en el postest, evidenciado en afirmaciones tales como: "Se puede decir que las relaciones mercantiles o económicas con Africa bicieron que gente infectada se trasladara, o twiera alguna transfusión con sangre no controlada, encuentros inseguros, etc.", elaborada para explicar el origen del VIH. Los cambios evidenciados en el conocimiento de la enfermedad también son significativos ya que mientras 13 estudiantes muestran un conocimiento adecuado, 26 lo hacen en el pretest por medio no sólo de un dominio mayor de síntomas, formas de prevención y contagio sino también en relación con un uso progresivamente más ajustado de una jerga científica adecuada para el contexto en el que fue solicitada la explicación (un examen final).

Por otra parte, en relación con la calidad argumentativa de los textos producidos se evidencia una progresión positiva en los mismos, es decir, una incorporación cada vez mayor de las componentes enseñadas. Los textos se revelan cada vez más sofisticados, en especial en la actividad en las que deben elaborar una explicación a una anciana de la zona de los Cárpatos - que cree que sus vecinos son vampiros - y a la que los estudiantes deben explicarle que, en realidad, son personas que padecen porfiria eritropoyética congénita o mal de Gunther ${ }^{3}$. En este caso la mayoría de los estudiantes muestran los mayores logros en tanto a las componentes retórica y pragmática, por medio de la utilización de recursos tales como metáforas, paráfrasis, utilización de lenguaje coloquial, ejemplos, apelación a la autoridad científica, y otras figuras. Para ilustrar las presentes afirmaciones se presentan dos producciones pertenecientes a un mismo

\footnotetext{
${ }^{3}$ ¿Vampiros en Valaquia? (ADÚRIZ-BRAVO, 2005) presenta una comparación entre el mito de los vampiros y la enfermedad.
} 
estudiante. La primera corresponde a una instancia previa a la enseñanza de las componentes de una argumentación y del modelo complejo de salud-enfermedad, la segunda corresponde a un momento postinstruccional.

1. Actividad: “¿Qué vieron hoy en la clase de educación para la salud?”. Se les solicitó a los estudiantes que imaginaran que llegan a su casa y su madre/padre les realiza esta pregunta. La actividad fue sugerida luego de realizar el relato de la peste negra medieval.

Lo que aprendimos boy fue un relato sobre la peste negra en la Edad Media donde Andrea nos leyó un texto explicando cómo la peste negra apareció y se propagó en la sociedad de la Edad Media viendo las consecuencias y causas que facilitaron su propagación.

2. Actividad: “¿Enfermos o vampiros?” Se les sugiere a los estudiantes que imaginen que estando de vacaciones por una aldea de los Cárpatos, encuentran a una viejita que, atada a antiguos prejuicios, cree que sus vecinos son vampiros. Ellos deben explicarle que en realidad son enfermos de porfiria.

Querría tener el honor de hablar con usted sobre los vampiros. En caso de aceptar, me gustaria que me contara la bistoria de esos sujetos. [Evidencia de ajuste a la componente pragmática: se utiliza un lenguaje coloquial sumamente adecuado al contexto.]

Sí, cómo no. Por lo que sé, hace muchos años existieron en este pueblo muchos vampiros que salian de noche para absorber [sic] la sangre de los habitantes para ser siempre jóvenes. ¿Y cómo eran? Eran pálidos, con dientes filosos y rojos y tenían mucho bello [sic] facial. Salian de noche porque el sol es su peor enemigo y el ajo los lastima asi como las cruces. [Evidencia de ajuste a la componente pragmática: el estudiante tiene en cuenta lo que el receptor sabe para apoyar en esos conocimientos la explicación que aportará.]

Me gustaria ir a eso. Encontré un libro de un importante biólogo que explica que estos vampiros no existen. [Evidencias de ajuste a la componente retórica: el estudiante recurre a la autoridad científica (el libro escrito por un biólogo) para dar credibilidad a su explicación.]

Pero su flacura y palidez se deben a la anemia por tenerproblemas en fabricar glóbulos rojos. La cosa del sol tiene que ver con esta enfermedad causando graves quemaduras en la piel cuando esta se vuelve muy sensible y es por ello que usan ropas amplias y oscuras. [...] ¿Y por qué hay gente que desapareció de estos pueblos?preguntó la viejita. La gente no despareció, simplemente se enfermaron y por eso dejaron de salir de día. [Evidencia de ajuste a la componente teórica: el estudiante muestra tener un conocimiento apropiado de la enfermedad. Usa vocabulario técnico adecuado al receptor. Por ejemplo, utiliza la expresión: "sensibilidad a 
la piel", en lugar de "actinismo", para referirse a uno de los síntomas de la enfermedad.]

[Evidencia de ajuste a la componente lógica: se visualiza un discurso ordenado, con coherencia global ya que el texto se comprende y puede ser leído de corrido y un uso adecuado de conectores.]

[Evidencia de ajuste a la componente pragmática: el estudiante recurre al uso de la estructura dialogal para estructurar la explicación, recurso sumamente adecuado al contexto y al receptor al que se la ofrecerá.]

$\mathrm{El}$ análisis de este fragmento y, en general, los resultados obtenidos en el presente trabajo permiten realizar aportes para la comprensión de las relaciones que se establecen entre el aprendizaje de la argumentación científica escolar y un modelo complejo de salud-enfermedad, ya que los mismos sugieren que el dominio de la estrategia argumentativa impacta positivamente en el aprendizaje de este contenido científico escolar. Los estudiantes que participaron de esta investigación produjeron textos no sólo más complejos y ricos desde la perspectiva de la estructura textual argumentativa, sino que mostraron haberse apropiado progresivamente de un modelo explicativo complejo de salud-enfermedad que pudieron aplicar con aceptable solvencia y ajuste, a los casos planteados. En relación con el dominio de la competencia argumentativa los trabajos pre y post instruccionales presentados muestran un dominio aceptable de las cuatro componentes que configuran una argumentación de acuerdo al modelo teórico presentado y al que adscribimos. Al mismo tiempo se identifica claramente un reconocimiento y dominio de la importancia del tener en cuenta el contexto (en este caso informal) y el formato (en este caso el diálogo) al momento de producir una argumentación solidaria con la perspectiva ilocutiva.

\section{Reflexiones finales}

La calidad de los textos producidos por los estudiantes que participaron de esta investigación puede ser analizada críticamente en el sentido de que persiste en algunos de ellos cierta pobreza en tanto a su estructura o que algunas componentes se encuentran poco desarrolladas o desdibujadas. Sin perjuicio de esto, las producciones más avanzadas de los estudiantes se muestran sensiblemente mejores a las iniciales, lo que nos permite sostener la afirmación de que el aprendizaje de los contenidos científicos en relación con la salud y la enfermedad y de la competencia argumentativa pueden mostrar progresos importantes en tanto se argumenta y se reflexiona sobre el proceso. La enseñanza de ambas temáticas en el marco de este trabajo se ha concebido teniendo en cuenta la relevancia que el lenguaje tiene en el aprendizaje y evaluando al diálogo como un elemento imprescindible para la co- construcción de conocimientos y a la argumentación en su doble vertiente: epistémica y favorecedora de procesos metacognitivos. (LEITAO, 2007).

Como plantea Jiménez Aleixandre y Federico Agraso (2009), en la tarea científica el lenguaje y la comunicación son elementos fundamentales; con ese mismo espíritu, la perspectiva sociocultural alertó acerca de la importancia que estos factores tienen en el aprendizaje y ahondó en la cuestión acerca de cómo las funciones mentales superiores - el aprendizaje de las ciencias en el presente trabajo - se produce en estrecha conexión con el contexto social. 
El presente trabajo se centró en una determinada población de escuela media, sin embargo, creemos - sin pretender realizar una generalización abusiva - que sus resultados podrían extrapolarse a otras comunidades del mismo nivel educativo.

\section{Referencias}

ADÚRIZ- BRAVO, A. Fostering model-based school scientific argumentation among prospective science teachers. US-China Education Review, Libertyville, v. 8, n. 5, p. 718-723, 2011.

. ¿Vampiros en Valaquía? Buenos Aires: Ministerio de Educación, Ciencia y Tecnologia, 2005. (Colección la ciencia, una forma de leer el mundo). Disponible en: $<$ http://planlectura.educ.ar/ pdf/literarios/vampiros_en_valaquia.pdf >. Acceso el: 07 ago. 2014.

BLISS, J.; MONK, M.; OGBORN, J. Qualitative data analysis for educational research: a guide to uses of systemics networks. London: Croom Helm, 1983.

BRUNER, J. Actos de significado: más allá de la revolución cognitiva. Madrid: Alianza, 1991.

CHION, A. F. R. Hablar y escribir ciencias. In: MEINARDI, E. (Comp). Educar en ciencias. Buenos Aires: Paidós, 2010. p. 163-190.

CHION, A. F. R. et al. Estudios sobre la enseñanza de la argumentación científica escolar. Enseñanza de las Ciencias, Barcelona, p. 1-5, 2005. (Número extra). Disponible en: < http://ddd.uab.cat/pub/ edlc/edlc_a2005nEXTRA/edlc_a2005nEXTRAp400estens.pdf >. Acceso el: 07 ago. 2005.

CHION, A. F. R.; ERDURAN, S.; ADURIZ- BRAVO, A. Argumentación científica escolar: consensuando su significado en clases de ciencias naturales de secundaria. In: CONGRESO IBEROAMERICANO DE EDUCACIÓN EN CIENCIAS EXPERIMENTALES, 3., 2004, Ciudad de Guatemala. Actas... Ciudad de Guatemala: Universidad de San Carlos, 2004. 01 CD-ROM.

CLAXTON, G. Aprender: el reto del aprendizaje contínuo. Barcelona: Paidós, 2001.

DRIVER, R.; NEWTON, P.; OSBORNE, J. Establishing the norms of scientific argumentation in classrooms. Science Education, Hoboken, v. 84, n. 3, p. 287-312, 2000.

DUCHL, R. Quality argumentation and epistemic criteria. In: ERDURAN, S.; JIMÉNEZ

ALEIXANDRE, M. P. (Ed.). Argumentation in science education: perspectives from classroombased research. [Berlin]: Springer, 2008. p. 159-179.

EDER, M. L.; ADÚRIZ-BRAVO, A. La explicación en las ciencias naturales y en su enseñanza: aproximaciones epistemológicas y didácticas. Revista Latinoamericana de Estudios Educativos, Manizales, v. 4, n. 2, p. 101-133, 2008. Disponible en: < http://latinoamericana.ucaldas.edu.co/ downloads/Latinoamericana4(2)_7.pdf >. Acceso el: 07 ago. 2014.

ERDURAN, S.; JIMÉNEZ ALEIXANDRE, M. P. (Ed.). Argumentation in science education: perspectives from classroom-based research. [Berlin]: Springer, 2008.

ERDURAN, S.; SIMON, S.; OSBORNE, J. TAPping into argumentation: developments in the application of Toulmin's argument pattern for studying science discourse. Science Education, Hoboken, v. 88, n. 6, p. 915-933, 2004.

IZQUIERDO, M. et al. Caracterización y fundamentación de la ciencia escolar. Enseñanza de las Ciencias, Barcelona, p. 79-92, jun. 1999. (Número Extra). 
IZQUIERDO, M.; ADÚRIZ BRAVO, A. Epistemological foundations of school science. Science $\boldsymbol{E}$ Education, Dordrecht, v. 12, n. 1, p. 27-43, 2003.

IZQUIERDO, M.; SANMARTI, N. Hablar y escribir para enseñar ciencias. Enseñanza de las Ciencias, Barcelona, n. 6, p. 135-136, 2001. (Número extra).

JACKSON, P. Sobre el lugar de la narrativa en la enseñanza. In: McEWAN, H.; EGAN, K. (Comp.). La narrativa en la enseñanza y la investigación. Buenos Aires: Amorrortu, 2005. p. 125-152.

JIMÉNEZ ALEIXANDRE, M. P. Diez ideas clave: competencias en argumentación y uso de pruebas. Barcelona: Graó, 2010.

JIMÉNEZ ALEIXANDRE, M. P.; DÍAZ DE BUSTAMANTE, J. Discurso de aula y argumentación en la clase de ciencias: cuestiones teóricas y metodológicas. Enseñanza de las Ciencias, Barcelona, v. 21, n. 3, p. 359- 370, 2003.

JIMÉNEZ ALEIXANDRE, M. P.; FEDERICO AGRASO, M. Justification and persuasion about cloning: arguments in Hwang's paper and journalistic reported versions. Research in Science Education, Dordrecht, v. 39, n. 3, p. 331-347, 2009.

JORBA, J.; GÓMEZ, I.; PRAT, A. Hablar y escribir para aprender: uso de la lengua en situación de enseñanza-aprendizaje desde las áreas curriculares. Barcelona: Síntesis, 1998.

KELLY, G.; TAKAO, A. Epistemic levels in argument: an analysis of university oceanography student's use of evidence in writing. Science Education, Hoboken, v. 86, n. 3, p. 314-342, 2002.

KEMMIS, S.; McTAGGART, C. Cómo planificar la investigación-acción. Barcelona: Alertes, 1988.

KEYS, C. Revitalising instructions in scientifics genres: connecting knowledge productions with writing to learn in science. Science Education, Hoboken, v. 83, n. 4, p. 115-130, 1999.

KUHN, D. Teaching and learning science as argument. Science \& Education, Dordrecht, v. 94, n. 5, p. 810-824, 2010.

LANGER, J. A.; APPLEBEE, A. N. How writing shapes thinking: a study of teaching and learning. Urbana: National Council of Teachers of English, 1987.

LEITAO, S. La dimensión epistémica de la argumentación. In: KRONMÜLLER, E.; CORNEJO,

C. Ciencias de la mente: aproximaciones desde Latinoamérica. Santiago de Chile: J. C. Sáez, 2007. p. $10-29$.

MAGLIO, F. La dignidad del otro: puentes entre la biología y la biografía. Buenos Aires: Libros del Zorzal, 2008.

MÁRQUEZ, C. La comunicación en el aula. In: MERINO RUBILAR, C.; GÓMEZ GALINDO, A.; ADÚRIZ-BRAVO, A. (Ed.). Área y estrategias de investigación en la didáctica de las ciencias experimentales. Bellaterra: Universitat Autónoma de Barcelona: Departament de Didáctica de la Matemática i de las Ciénces Experimentals, 2008. p. 127-148.

MÉHUET, M.; PSILLOS, D. Teaching-learning sequences: aims and tools for science education research. International Journal of Science Education, London, v. 26, n. 5, p. 515-535, 2007.

MEINARDI, E. et al. Teaching scientific argumentation to prospective biology teachers. In: INTERNATIONAL HISTORY PHILOSOPHY \& SCIENCE TEACHING CONFERENCE, 7., 2004, Winnipeg, Canada. Proceedings... Winnipeg: University of Winnipeg, 2004. p. 662-665. 
MEINARDI, E.; GONZÁLEZ GALLI, L. Por un ambiente sano: enseñar mejor. Buenos Aires: Ediba Eudeba, 2009.

NORRIS, S. et al. A theoretical framework for narrative explanation in science. Science $\boldsymbol{\&}$ Education, Dordrecht, v. 84, n. 4, p. 535-563, 2005.

PRAIN, V.; HAND, B. Students perceptions of writing for learning in secondary school science. Science Education, Hoboken, v. 83, n. 2, p. 151-162, 1999.

RIVARD, I.; STRAW, S. The effect of talk and writing on learning science: an exploratory study. Science Education, Hoboken, v. 84, n. 5, p. 566-593, 2000.

SAMPSON, V.; CLARK, D. Assesment of the ways studentes generate arguments in science education: current perspective and recommendations for future directions. Science Education, Hoboken, v. 92, n. 3, p. 447-472, 2008.

SANMARTÍ PUIG, N. Aprende ciéncies tot aprenent a escriture ciéncie. Barcelona: Ediciones 62, 2003.

SANMARTÍ PUIG, N. Enseñar a elaborar textos científicos en las clases de ciencias. Alambique: didáctica de las ciencias experimentales, Barcelona, n. 12, p. 51-61, 1997.

SANMARTI PUIG, N. 10 ideas clave: evaluar para aprender. Barcelona: Graó, 2007.

SARDÁ JORGE, A.; SANMARTÍ PUIG, N. Enseñar a argumentar científicamente: un reto de las clases de ciencias. Enseñanza de las Ciencias, Barcelona, v. 18, n. 3, p. 405-422, 2000.

SUTTON, C. Ideas sobre la ciencia e ideas sobre el lenguaje. Alambique: didáctica de las ciencias experimentales, Barcelona, v. 12, p. 8-32, 1997.

VYGOTSKY, L. Pensamiento y lenguaje. Buenos Aires: La Pléyade, 1977.

WASSERMAN, S. El estudio de casos como método de enseñanza. Buenos Aires: Amorrortu, 2006. 
Apéndice A. Red sistémica correspondiente a la componente retórica de la actividad: "Explicación a una anciana de los Cárpatos"

Las categorías principales se ubican a la izquierda y las variables y subvariables a la derecha; el detalle y la precisión aumentan conforme la lectura se realiza de izquierda a derecha. Los términos del final son "textuales" o lo más parecido posible a los usados por los autores de los textos, lo que favorece la transparencia de los datos.

La red puede ser leída en ambas direcciones, es decir, puede partirse de un fragmento de un texto elaborado por un alumno y realizar un recorrido hacia la izquierda de manera tal de identificar con qué subvariable o variable se lo ha identificado y a qué categoría pertenece la misma. En sentido inverso es posible enfocar una categoría y descomponer la misma en variables y subvariables leyendo las mismas hacia la derecha hasta llegar al dato preciso, es decir, al indicador: textos producidos por los alumnos que se constituyen en la representación de la categoría.

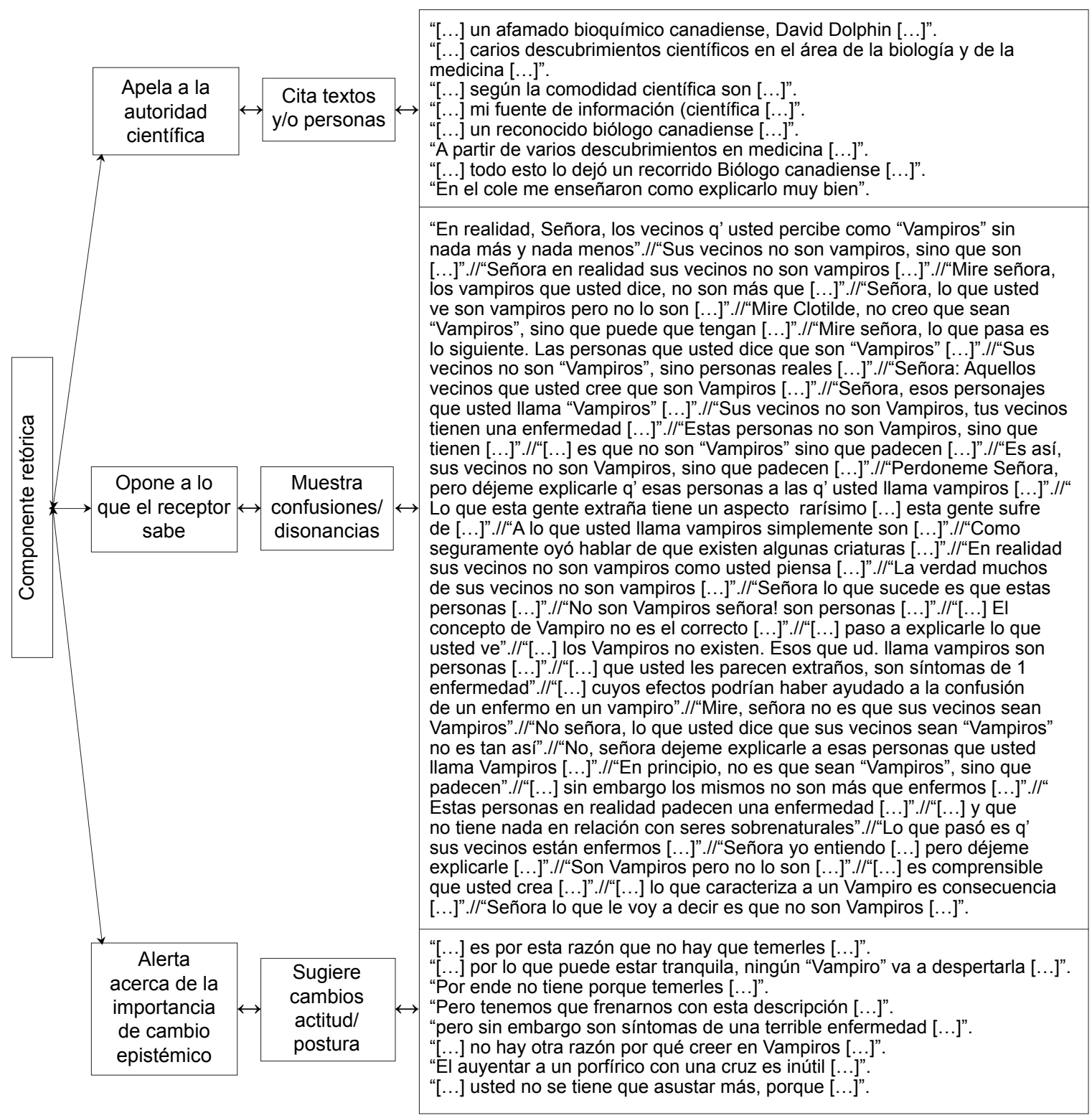

